\title{
SWOT Analysis of Micro Entrepreneurship and Start-ups in Haryana
}

\author{
Jyoti Yadav ${ }^{1, *}$, Neelam Gulati² \\ ${ }^{1}$ Institute of Management Studies and Research, Maharishi Dayanand University, Rohtak, India \\ ${ }^{2}$ Dayanand Anglo-Vedic Institute of Management, Faridabad, India
}

Email address:

j4jyotiyadav@gmail.com (J. Yadav)

${ }^{*}$ Corresponding author

To cite this article:

Jyoti Yadav, Neelam Gulati. SWOT Analysis of Micro Entrepreneurship and Start-ups in Haryana. International Journal of Business and Economics Research. Vol. 8, No. 6, 2019, pp. 399-405. doi: 10.11648/j.ijber.20190806.20

Received: July 30, 2019; Accepted: August 29, 2019; Published: November 22, 2019

\begin{abstract}
MSMEs (Micro, Small and Medium Enterprises) have been globally considered as an engine of economic growth and as key instruments for promoting equitable development in most of the economies of the world. The MSMEs constitute over $90 \%$ of total enterprises in most of the economies and are credited with generating the highest rates of employment growth. They not only play crucial role in providing large employment opportunities at comparatively lower capital cost than large industries but also help in industrialization of rural \& backward areas, which in turn, reduces regional imbalances, assuring more equitable distribution of national income and wealth. Micro, Small and Medium Enterprises (MSME) and Startups play vital role in the process of development in India. It generates employment at low cost and helps the society to move on the path of prosperity \& growth. As more than $65 \%$ of Indians live in villages and as there is little scope for establishment of Large-scale industries in these areas, MSME is an important aspect with regard to development of rural areas. Even though the State has huge potential for industrialization, especially for MSME sector, its potential has not been fully harnessed so far. Thus the present paper is an attempt towards finding out the Strengths, Weaknesses, Opportunities and Threats of MSMEs and Start-ups in the State of Haryana. The present study proposes interprets, analyse, and understand the challenges faced by the Micro entrepreneurs and their business in Haryana State. By virtue of so, the study will prove to be a panacea for Micro entrepreneurs and start-ups. The study further suggests them how to increase the innovativeness, decision making and diversification of their businesses in Haryana state.
\end{abstract}

Keywords: Micro, Small and Medium Enterprises (MSMEs), Start-ups, Strengths, Weaknesses, Opportunities, Threats

\section{Introduction}

Sustainable development of any economy depends not only on large scale organized industries but also equally dependent on other employment generation avenues to utilize locally available natural and human resources. Micro, Small and Medium Enterprises (MSME) [1] is one such sector. MSMEs have been globally considered as an engine of economic growth and as key instruments for promoting equitable development.

The MSMEs [2] constitute over $90 \%$ of total enterprises in most of the economies and are credited with generating the highest rates of employment growth. These not only play crucial role in providing large employment opportunities at comparatively lower capital cost than large industries but also help in industrialization of rural \& backward areas, which in turn, reduces regional [3] imbalances, assuring more equitable distribution of national income and wealth. MSMEs are complementary to large industries as ancillary units and this sector contributes enormously to the socio-economic development of the country. In India too, the MSMEs play a pivotal role in the overall industrial economy of the country. In recent years the MSME sector has consistently registered higher growth rate compared to the overall industrial sector.

India is currently placed 3rd on the global list of the top five startup communities. The country has been able to establish a strong footprint in becoming a globally recognized Startup Nation. India has improved its innovation ranking in GII (Global Innovation Index) to reach 66th 
position from its last year's rank of 81 st, India is the topranked economy in Central and Southern Asia, showing particular strengths in tertiary sector and R\&D [4], the quality of its universities and scientific publications, its market sophistication and ICT service exports where it ranks first in the world. India also over- performs in innovation relative to its GDP. It ranks second on innovation quality amongst middle-income economies, overtaking Brazil. Several Indian companies that started as humble startup have been able to make a mark in the global investor fraternity.

Unlike most of the developed economies [5], India is a young country with about $63 \%$ population currently being in the working age group of 15-59 years. It is the energy and enthusiasm of this youth which is the real driving force behind the entrepreneurial and Startup success. The perfect blend of rising aspirations of youth, audacity to pursue their interest and the enterprising bent of mind is helping the country to emerge as the leaders of new age entrepreneurship. The government is keen to channelize this energy by providing the right ecosystem, proactive policies and ready talent pool to the budding entrepreneurs.

Haryana is the home land of various new age entrepreneurs and is birth place of the many successful business magnets and large industrial houses of India. Gurgaon the IT city of Haryana, has evolved as a technology startup hub of India and has nurtured many successful startups, which now have become big brands. Haryana's economic growth has been exemplary and despite being geographically small, its contribution to the national economy is significant at nearly 3.5 percent of the GDP. While the State economy is home to a strong manufacturing sector, it is maturing at a fast pace with the Services and IT sectors gaining ground, making Haryana well poised to initiate the startup revolution.

The Government of Haryana is keen to further harness the potential of young entrepreneurs by providing the necessary policy push and maximum convergence by linking the policy with the larger perspectives of Government of India initiatives including Digital India, Make in India, Standup \& Startup India and Skill India. At this juncture, when Government of India is fiercely pursuing the goal of creating an enterprising India, State government also need to take initiative on its part to reinforce these initiatives by creating the enabling atmosphere; it is imperative for the State Government to place Startups and entrepreneurship at the core of policy making and come up with the dedicated policy to address the issues which are unconventional in nature and need a different \& distinctive lens to help them in mushrooming. The core objective of this policy is to provide distinct levels of government support at every stage and to create a holistic and sustainable ecosystem.

\section{Objectives of the Study} [6].

This study was conducted with the objective of the study

i. Assessing the potential strength of the MSME sector. ii. Examining the issues pertaining to various weaknesses affecting the sector.

iii. Highlighting the opportunities vide policy interventions by the Government as well as RBI for its growth.

iv. Analyzing the threats of the sector which occur regularly.

v. Suggesting measures for improvement of the MSME sector, by limiting the threats and weaknesses.

\section{Definitions of Micro, Small \& Medium Enterprises}

\subsection{Micro, Small and Medium Enterprises Development (MSMED) Act, 2006 [7]}

The Government of India [8] has enacted the Micro, Small and Medium Enterprises Development (MSMED) Act, 2006 on June 16, 2006 [9] which was notified on October 2, 2006. With the enactment of MSMED Act 2006 [10], the paradigm shift that has taken place is the inclusion of services sector in the definition of Micro, Small and Medium Enterprises, apart from extending the scope to Medium Enterprises.

\subsection{Micro, Small and Medium Enterprises}

Micro entrepreneurs usually operate unorganized. By promoting the Micro entrepreneurs, there will be a possibility to turn them into Micro, Small and Medium Enterprises (MSME). They play a decisive role in the development of economy of developing countries like India. In India, MSME contribute nearly 8 percent of the country's GDP [11], 45 percent of the manufacturing output and 40 percent of the exports. They provide the largest share of employment after agriculture (Ministry of Micro, Small \& Medium Enterprises). Micro entrepreneur is synonym for Selfemployment.

Micro entrepreneurs play extremely significant role in Indian economy. In Haryana only there are 8.66 lakh MSME enterprises giving employment to 18.84 lakh people (Annual Report, 2012-13 Ministry of MSME). The $2^{\text {nd }}$ National award for Micro \& Small enterprises rendering services has been awarded jointly to entrepreneurs from Haryana and Odisha. MSME [12] helps in industrialization of rural and backward areas, thereby, reducing regional imbalances, assuring more equitable distribution of national income and wealth.

The MSMED Act, 2006 [13] defines the Micro, Small and Medium Enterprises based (i) on the investment in plant and machinery for those engaged in manufacturing or production, processing or preservation of goods and (ii) on the investment in equipment for enterprises engaged in providing or rendering of Services.

\section{Start-ups}

A Start-Up [14] is an entrepreneurial venture which is typically a newly emerged, fast- growing business that aims to meet a market place need by developing or offering an 
innovative product, Process or service. Start-ups are usually an entity such as a small business, a partnership or an organization designed to rapidly develop a scalable business model. Start-ups are a company that is in the first stage of its operation.

Start-ups [15] are often initially bankrolled by their entrepreneurial founders as they attempt to capitalize on developing a product or service for which they believe there is a demand. Due to limited revenue or high costs, most of these small -scale operations are not sustainable in the long term without additional funding from venture capitalists.

On February 18, 2016, the Ministry of Commerce and Industry released a notification to define 'startups'. There were many points that were consistent from the speech given by Prime Minister Narendra Modi during the unveiling of the 'Startup India, Standup India' policy. According to the government notification, an entity will be identified as a startup.

a) Till up to five years from the date of incorporation.

b) If its turnover does not exceed 25 crores in the last five financial years.

c) It is working towards innovation, development, deployment, and commercialization of new products, processes, or services driven by technology or intellectual property.

Provided further that in order to obtain tax benefits a startup so identified under the above definition shall be required to obtain a certificate of an eligible business from the Inter-Ministerial Board of Certification consisting of: a) Joint Secretary, Department of Industrial Policy and Promotion, b) Representative of Department of Science and Technology, and o) Representative of Department of Biotechnology.

\section{Vision, Mission and Objectives of Entrepreneur and Start-ups Policy of Haryana, 2017}

\subsection{Vision}

To become a resourceful \& inventive Start-up Hub of the country by supporting \& assisting the new-age innovators and entrepreneurial talents across the State.

\subsection{Mission}

a) Establishing an IT Startup Hub in Gurugram.

b) Build Incubation center in all part of State

c) Creating a sustainable ecosystem of Innovation, R\&D and Engineering in the state.

d) Aligning Haryana with the 'Startup India' flagship initiative of the Govt. of India.

e) Enhancing links between universities, research institutions and the business community.

f) Promoting businesses that are aligned with a region's unique areas of opportunity.

\subsection{Objectives}

a) Attract INR 1500 Crores investments into the Incubation and Startup Ecosystem in Haryana during policy period.

b) Establish at least 22 Technology /Business Incubators / Accelerators in each of the different sectors in every district of Haryana.

c) Develop 1 million sq. $\mathrm{ft}$. of Incubation/ Common Office space.

d) Facilitate Venture Capital funding of a minimum of INR 200 Crore.

e) Encourage/Facilitate/Incubate at least 500 startups.

\subsection{Definition and Eligibility for Start-ups in Haryana}

Startup means an entity (Private, Public, Proprietary, Partnership Firm), incorporated in India [16-17].

i. As a private limited company (as defined in the Companies Act, 2013) or registered as a Partnership firm (registered under Section 59 of the Partnership Act, 1932) or a limited liability partnership (under the Limited Liability Partnership Act, 2008) in India.

ii. Not prior to seven years and in the case of Biotechnology Companies this period shall be up to 10 years.

iii. With annual turnover not exceeding INR 25 crore in any preceding financial year.

iv. Working towards innovation, development or improvement of products or processes or services, or if it is a scalable business model with a high potential of employment generation or wealth creation.

v. Provided that such entity is not formed by splitting up, or reconstruction, of a business already in existence and should not have been formed by the demerger or reconstitution of a business already in existence.

vi. Provided that such entity is not a holding company and it is not a subsidiary of any firm already in existence or except the subsidiary of any startup.

\subsection{Eligibility Conditions}

1. Location: The company / entity be registered in Haryana under the Haryana Shops and Commercial Establishment Act, 1958.

2. Employment: The company employs at least 50 (fifty) per cent of its total qualified workforce in Haryana, which shall not include contract employees.

\subsection{Exit Conditions}

1. If the company is found guilty on any charges of fraud or if the company is found to have made any false declarations to claim any benefits from or derived under this policy. Legal action shall be initiated to recover all financial assistance provided to such an entity.

2. Once an entity ceases to be recognized as a start-up; the Government or entity through which the Government makes its investment will be eligible to exit its 
investment in the start-up and guidelines for exit will be framed for channelizing investments into the start-up.

\subsection{Certification of Startups for Haryana-Startup Policy Benefit}

All applications of potential startups received shall undergo a preliminary examination by Startup wing of HARTRON. After preliminary examination a list of shortlisted applications shall be tagged to the concerned subject related incubators. The Incubators after the incubation process shall prepare a proposal on the following issued.

i. The amount of funding assistance required at various stages.

ii. Any requirement of common infrastructure or other infrastructure created under this policy.

iii. Any assistance as envisaged under this policy.

iv. Business Plan.

The list of such recommendations/proposals of the incubators shall be placed before the Policy Implementation Committee. The Committee shall examine these recommendations and recommend for certification of startups. It is only after this certification that the startups shall be eligible for financial incentives under this policy. Or, startup recognized by DIPP and fulfilling the above mentioned eligibility criteria may avail the financial incentives under this policy.

\section{SWOT Analysis of SME's and Start-ups in Haryana}

SWOT [18] analysis is a strategic method used to evaluate the Strengths, Weaknesses, Opportunities, and Threats involved in a project or in a business venture. It involves identifying the internal and external factors that are favorable and unfavorable to achieve that objective.

In brief,

1. Strengths: are the characteristics of the business or team that give it an advantage over others in the industry.

2. Weaknesses: are characteristics that place the firm at a disadvantage relative to others.

3. Opportunities: are external chances to make greater sales or profits in the environment.

4. Threats: are external elements in the environment that could cause trouble for the business.

\subsection{Strengths}

The points of Strengths for growth in the MSMEs sector and Start-ups are enormous due to the following factors [19]:

i. MSMEs can be started at a very low cost.

ii. Adapting to change is crucial in these sectors; not being tied to any bureaucratic inertia, it is typically easier to respond to the marketplace quickly.

iii. Good customer relation results in greater accountability and maturity. Customers who are treated like family are more likely to return to that business in the future.

iv. Independence to work for own firm is another advantage of these sectors.

v. Ability to innovate and create new products and services more rapidly and creatively than larger companies that are delayed in bureaucracy.

vi. A small firm has also the ability to modify its products or services in response to unique customer needs. The average entrepreneur or manager of a small business knows his customer base far better than in a large company.

vii. Cater to customer needs. If a modification in the products or services offered or even the business's hours of operation would better serve the customers, it is possible for a small firm to make changes.

viii. The people involved - the entrepreneur, any partners, advisers, employees, or even family members - have a passionate, almost compulsive, desire to succeed. This makes them work harder and better.

\subsection{Weaknesses [20]}

i. It can be difficult to reach enough potential customers to establish a successful base of customers. Potential customers might be less likely to do business with a small business that does not offer a well-known brand of products or services.

ii. One of the largest weaknesses for small business owners is to raise finance. Many business owners invest their own money at the start of a business or if the business falls upon hard times because institutional lenders like banks and government financial corporations are generally reluctant to advance money to these small units.

iii. Small business owner has to bear high cost of production, which acts as one of the weakness for the small businesses.

iv. Most of small scale businesses do not have skilled personnel. Due to which these businesses lack in identification of industrial projects for development consultancy and counseling services and providing industrial training and skill formation.

v. Small businesses do not use Information technology and its applications such as the designing of prototype machines for product identified according to country resources and requirements.

vi. Many times it becomes very difficult to obtain the permission of and license from, the Industrial Development of the state, local bodies etc.

vii. Marketing is one of the weaknesses for small businesses.

viii. Besides these, the entrepreneurs face many problems in marketing due to.

ix. Lack of standardization.

$\mathrm{x}$. Poor designing.

xi. Poor quality.

xii. Lack of quality control.

xiii. Lack of precision. 
xiv. Poor finish.

xv. Poor bargaining power.

xvi. Lack of service after sales.

xvii. Scale of production.

xviii. Brand preferences.

xix. Distribution contacts.

xx. Lack of knowledge of marketing.

xxi. Competitive marketing.

xxii. Ignorance of potential market.

\subsection{Threats}

Some of the threats related to MSMEs and Start-ups are [21]:

1. Slow Payments: While large corporations and banks have been fortified with ample low-cost cash to buy small businesses" products and services, they continue to pay slowly, bargain harder and demand more concessions from powerless small businesses who are selling their souls "where the money is".

2. New costs, taxes and compliance: As social causes like sustainability, diversity, healthcare and fair taxation are being legislated by governments and lobbied into favorable terms for corporations, small business is getting choked. Now, the new costs, taxes and compliance rules are sapping the will of owners to believe that they should risk, invest and remain confident in their businesses.

3. Approved vendor programs force buying solely on price: To shift responsibility and outsource their liability, corporations and governments are hiring third party sourcing companies whose objective is to reduce small business vendor power and commoditize their products and services.

\subsection{Opportunities}

\subsubsection{Opportunities for Micro Entrepreneurs [22]}

1. Less capital intensive.

2. Most important employment generating sector.

3. Effective tool for promotion of balanced regional development.

4. It is extensively promoted and supported by the Government.

5. Finance and subsidies are provided by the government.

6. Produced goods are purchased by the Government.

7. Procurement of machinery and raw material.

\subsubsection{Opportunities for Start-ups in India}

India has the largest youth population, which is the largest driver for innovation, workforce, talent and future leaders. India has its own challenges of education, health, infrastructure and the rising gap between India and Bharat. This presents big opportunity for start-ups to solve a variety of problems. India has the population of 1.3 billion people; the country's middle class is growing along with the consumers. The large diversity in the India's population makes a strong case for a rich services and products economy. Start-ups should look at banks; our banking system has reaped the maximum benefit of our population size.

i. Connectivity

Indian telecom industry has nearly 100 crore subscribers, mobile connectivity has made inroads in the rural and urban population. Government of India's digital push is going to improve connectivity and data to the next level. The race to cheapest data has started and disruption is certain. The cheap data has helps everyone to get their hands on it, start-ups will have an easier time to tap into markets, territories and even traditional businesses.

ii. De-globalization

Critics will argue that this will be a challenge, however, ever coin has two sides; it is a challenge for some, and opportunity for the others. Brexit added fuel to the fire, while the new president of The USA has given early indications of lower corporate taxes, and destination taxes for US based corporations. Make in India, is also a part of this de globalised world, where we are promoting to make in India rather than anywhere else in the world. This is an opportunity for the Indian start-ups, more importantly, lesser brain drain, companies abroad will look to hire from India, and therefore greater talent pool will be available for start-ups.

India is a more closed economy as compared to China, and we do have substantial exports to the US, but this will be unaffected, although de-globalisation could have adverse effect on larger corporations who will scale down operations and become more frugal, this would also present opportunities for start-up companies to fill the void.

In India, the opportunities for the start-ups are immense, but so are the challenges. It will take combined efforts from the government and the start-ups to overcome these challenges.

Some of the other opportunities available for start-ups are as follows;

i. Consumer privacy protection.

ii. Counterterrorism technologies.

iii. Cyber security services to protect enterprises.

iv. Financial tech in emerging markets.

\section{Recommendations}

In this backdrop, the present study proposes interprets, analyse, and understand the challenges faced by the Micro entrepreneurs and their business in Haryana State. By virtue of so, the study will prove to be a panacea for Micro entrepreneurs and start-ups. The study further suggests them how to increase the innovativeness, decision making and diversification of their businesses in Haryana state.

Recommended Suggestions for Pushing the MSME Sector in rural Haryana

Interventions by Government / Regulators

\subsection{With Regard to Policy and Regulation}

1. Single Window System for regulatory clearances for MSME is already in place which needs to be activated. It may be covered under Public Service Guarantee Act of the State Government which may help time bound clearance for the startup of the projects. 
2. To address the issue of infrastructure in rural areas, State Government may contemplate creation of industrial estates and marketing hubs by using Government land in these districts to create a facilitator environment for encouraging MSME sector.

3. The mandated 20 per cent procurement from MSME sector by PSUs / Government departments needs to be followed in letter and spirit and should be properly monitored.

4. A sub-limit fixing 50 percent procurement from MSMEs of the State and rest 50 per cent from open market could be considered.

5. The State Government may issue an instruction to its PSUs to ensure that all dues have been paid to MSME entrepreneurs by them against receivables within specified time as per the existing rule before preparation of the final audit report of PSUs of the State.

6. Rationalization of the tax structure of the State will provide a level playing field to the local MSME entrepreneurs for marketing their products.

\subsection{With Regard to Infrastructure}

1. The State Government may improve capital investment in the State particularly for creation of infrastructures like road, rail and telecom networks, water-ways, uninterrupted power supply, last mile connectivity, dry and cold storage, processing unit's etc. district wise.

2. Infrastructure should be developed with cluster based approach for comprehensive development of the MSME sector. A district based cluster model may be suitable in case of Odisha keeping in view concentration of skills and products in specific area.

3. Skill Development and Capacity Building.

4. A district-wise system of periodical interaction between entrepreneurs (both existing and emerging), bankers and concerned Government officials to share developments in the sector may be put in place. Platform can be created for sharing of experience of successful rural entrepreneurs through Television or Radio.

5. TV programs can also broadcast for creating awareness and providing basic inputs to the upcoming entrepreneurs.

6. Capacity building efforts like skill development, entrepreneur hand holding, market match making etc., may be made on a continuous basis to create demand for credit and enhance the credit absorption capacity.

7. As a long term initiative, skill and entrepreneurship development programs may be made a part of the school / college curriculum to develop future entrepreneurs.

\section{References}

[1] Jewalikar, Ajay D., and Abhijeet Shelke. "Lean Integrated Management Systems in MSME Reasons, Advantages and Barriers on Implementation." Materials Today: Proceedings 4, no. 2 (2017): 1037-1044.
[2] Tripathi, Purnendu, and Siran Mukerji, eds. Handbook of Research on Technology-Centric Strategies for Higher Education Administration. IGI Global, 2017.

[3] Singh, Davinder, Jaimal Singh Khamba, and Tarun Nanda. "Exploring the Determinants of Technology Innovation in MSMEs." In International Journal of Engineering Research in Africa, vol. 13, pp. 103-115. Trans Tech Publications, 2015.

[4] Maheshkar, Snehal Pravin. "Innovation and Inclusiveness through Knowledge Management in Indian SMEs." In Knowledge Integration Strategies for Entrepreneurship and Sustainability, pp. 95-113. IGI Global, 2018.

[5] Vaidya, Shipra. Developing Entrepreneurial Life Skills: Creating and Strengthening Entrepreneurial Culture in Indian Schools. Springer Science \& Business Media, 2014.

[6] Srinivasan, R. Driving the economy through innovation and entrepreneurship: Emerging agenda for technology management. Edited by Chiranjit Mukhopadhyay, K. B. Akhilesh, Anjula Gurtoo, Parthasarathy Ramachandran, Parameshwar P. Iyer, M. Mathirajan, and MH Bala Subrahmanya. Springer India, 2013.

[7] Das, Keshab, ed. Globalization and standards: Issues and challenges in Indian business. Springer, 2014.

[8] Singla, Anju, and Parul Grover. "Growth and Financing of MSMEs: A Case Study of Punjab and Haryana." Asia-Pacific Journal of Management Research and Innovation 8, no. 3 (2012): 315-321.

[9] Mishra, Aswini Kumar, Vairam Arunachalam, and Debasis Patnaik. Current Issues in the Economy and Finance of India. Springer, 2018.

[10] Joshi, Manoj, and Apoorva Srivastava. "I have a dream: Ayuvayur Pharmaceuticals." Emerald Emerging Markets Case Studies 3, no. 1 (2013): 1-10.

[11] Chawan, Anup, and Hari Vasudevan. "Knowledge Management Practices in Indian Manufacturing MSMEs: Challenges and opportunities." Procedia Engineering 97 (2014): 1784-1787.

[12] Syal, S., Role of MSMEs in the growth of Indian economy. Glob. J. Commer. Manag. Perspect, 4(5) (2015).

[13] Kumar, Raj, and Abhijeet Biswas. "Innovative Financing and its Implications on MSME Sector in India." In Handbook of Research on Promotional Strategies and Consumer Influence in the Service Sector, pp. 421-433. IGI Global, 2016.

[14] Bartolini, Antonio, Roberto Cippitani, and Valentina Colcelli. "Dictionary of Statuses within EU Law."

[15] Sharma, Poonam, and Swati Rajput, eds. Sustainable smart cities in India: Challenges and future perspectives. Springer, 2017.

[16] Munshi, Angad. "Assessment of Competitiveness of Foodtech Start-ups in India." Indian Journal of Public Administration65, no. 1 (2019): 201-224.

[17] Birudavolu, Sriram, and Biswajit Nag. Business Innovation and ICT Strategies. Palgrave Macmillan, 2019.

[18] Ota, Hiroshi. "Japanese universities' strategic approach to internationalization: Accomplishments and challenges." In Emerging international dimensions in East Asian higher education, pp. 227-252. Springer, Dordrecht, 2014. 
[19] Jianzhong, Li. "Notice of Retraction Fast growth of new ventures through disruptive innovation: A case study of Ctrip." In 2010 2nd IEEE International Conference on Information Management and Engineering, pp. 344-348. IEEE, 2010.

[20] Manivannan, M. P., P. Raj Mohan, and P. S. S. Srinivasan. "Studies on environment, health and safety (ehs) practices in a small scale and large scale Indian industry."
[21] "Marketing Super Powder Clothes Washing Powder in Malaysia." University/Business and Administrative studies/Marketing, 2012-04-19.

[22] Dhiman, Mohinder Chand. "An investigation of e-HRM practices in Indian tourism and hospitality industry." In International Tourism and Hospitality in the Digital Age, pp. 88-102. IGI Global, 2015. 